J-DEPACE, Volume. 2, Nomor. 2, Desember 2019, Hal 157 - 170

Tersedia online di :http://jurnal.lpmiunvic.ac.id/index.php/jpkm

\title{
PENGGUNAAN BAHASA INDONESIA YANG BAIK DAN BENAR DALAM BERKOMUNIKASI
}

\author{
La Ode Madina, Maya Pattiwael, Fensca F Lahallo, Frits Rupilele, Aram Palilu \\ Universitas Victory Sorong \\ email : laodemadinanoken@gmail.com
}

\begin{abstract}
ABSTRAK
Penggunaan Bahasa Indonesia yang baik dan benar secara perlahan telah terkikis oleh adanya kemajuan teknologi yang semakin berkembang, sehingga para kaum muda di zaman sekarang kurang memperdulikan penggunaan bahasa Indonesia yang tepat dan menyebabkan kedudukan bahasa Indonesia semakin tertinggal. Pengabdian masyarakat yang dilakukan di Panti Asuhan Emiyo Dere Keluruhan Kladufu Distrik Sorong Timur berupa pemberian materi dengan metode pembelajaran bagi peserta didik yang berasal dari Sekolah Menengah Pertama (SMP) dan Sekolah Menengah Atas (SMA), bertujuan untuk meningkatkan kesadaran terhadap penggunaan bahasa Indonesia yang baik dan benar. Bahasa Indonesia yang benar adalah bahasa Indonesia yang digunakan sesuai dengan kaidah bahasa Indonesia yang berlaku. Kaidah bahasa Indonesia itu meliputi kaidah ejaan, pembentukan kata, kalimat, dan paragraf. Penghematan kata dalam bahasa Indonesia diupayakan agar tidak merusak kaidah bahasa, apalagi menimbulkan salah paham. Kesalahan yang terjadi biasanya dalam pembentukan kata, pemilihan kata, penyusunan kalimat, penerapan ejaan, dan surat menyurat. Hasil akhir dari kegiatan ini berupa penyerahan bantuan kepada anak-anak panti asuhan.
\end{abstract}

Kata kunci : Bahasa Indonesia, Kaidah bahasa, Komunikasi

\begin{abstract}
The use of Indonesian language that is well and truly finished has been eroded by the existence of increasingly evolving technology, so that young people today are less concerned with the use of the correct Indonesian language and using the Indonesian language position more quickly. Community service provided at the Emiyo Dere Orphanage in East Sorong District Kladufu consists of teaching materials used for students from junior high schools and senior high schools, as well as assistive devices that can be used for Indonesian good and right. Indonesian is truly Indonesian that is used in accordance with Indonesian rules. Indonesian language rules that contain spelling rules, word formation, sentences, and paragraphs. Efforts to save words in Indonesian are strived so as not to damage the rules of language, instead they cause misunderstanding. Errors that occur in the preparation of words, choice of words, preparation of sentences, the application of spelling, and correspondence. The final results of this activity provide assistance to orphanage children.
\end{abstract}

Keywords: Indonesian, Language rules, Communication 


\section{PENDAHULUAN}

Bahasa Indonesia ditetapkan sebagai bahasa Negara sesuai dengan yang tercantum dalam UUD 1945 pasal 36 yang menyatakan bahwa "Bahasa Negara adalah Bahasa Indonesia”. Oleh sebab itu, banyak Perguruan Tinggi dan sekolah-sekolah di Indonesia yang menambahkan Bahasa Indonesia dalam kurikulumnya. Materi yang diajarkan dalam pelajaran Bahasa Indonesia menjadi semakin popular dan menarik karena banyak pelajar luar negeri yang juga mempelajari tentang Bahasa Indonesia. Namun disamping itu, materi tentang Bahasa Indonesia juga dianggap sebagai pelajaran yang mudah atau biasa saja. Menurut Setiawati (2008), Bahasa Indonesia yang merupakan bahasa Nasional telah menjadi alat komunikasi yang efektif bagi terjalinnya hubungan antar etnik di Indonesia.

Penggunaan bahasa Indonesia yang baik dan benar merupakan suatu keharusan bagi rakyat Indonesia seperti yang tertuang dalam Peraturan Presiden Republik Indonesia nomor 63 tahun 2019 tentang Penggunaan Bahasa Indonesia. Berbahasa Indonesia yang baik dan benar dapat diartikan pemakaian ragam bahasa yang serasi dengan sasarannya dan yang di samping itu mengikuti kaidah bahasa yang benar (Alwi, dkk., 2010). Namun, penggunaan bahasa Indonesia yang baik dan benar di zaman sekarang sungguh memprihatinkan. Kemajuan teknologi yang semakin berkembang, memaksa para kaum muda di zaman sekarang kurang memperdulikan penggunaan bahasa Indonesia yang tepat. Anak muda sekarang lebih cenderung menggunakan bahasa atau ungkapan yang sedang nge-trend di seluruh dunia. Pengaruh sosial media dapat memenuhi aspek fungsi definisi bahasa Indonesia yang tepat, sehingga ini membuat kedudukan bahasa Indonesia semakin terjepit. Kita sering mendengar orang berdalih bahwa berbahasa itu yang terpenting lawan berbicara dapat memahami informasi yang kita sampaikan, dan tidak harus menggunakan bahasa yang baik dan benar sebagaimana yang diatur dalam bahasa Indonesia. Pretensi itu berkembang menjadi sebuah aksioma di tengah masyarakat dan akibatnya adalah bahasa Indonesia menjadi terabaikan.

Adanya aturan baku tentang penggunaan bahasa Indonesia yang baik dan benar (formal), masih saja disalahgunakan oleh sebagian masyarakat kita. Hal ini dapat kita lihat dari perilaku berbahasa masyarakat kita dewasa ini. Sikap bangsa Indonesia terhadap bahasa Indonesia cenderung ambivalen, sehingga terjadi dilematis. Artinya, di satu pihak kita menginginkan bahasa Indonesia menjadi bahasa modern dan dapat mengikuti perkembangan zaman serta mampu merekam ilmu pengetahuan dan teknologi global, 
tetapi di pihak lain kita telah melunturkan identitas dan citra diri itu dengan lebih banyak mengapresiasi bahasa asing sebagai lambang modernisasi. Atas dasar itu, tidak heran jika para remaja masa kini lebih cenderung menggunakan bahasa asing atau bahasa gaul sebagai bagian dari hidupnya jika mereka tidak ingin disebut ketinggalan zaman.

Dalam upaya meningkatkan kesadaran terhadap penggunaan bahasa Indonesia yang baik dan benar, maka perlu dilakukan pembinaan terhadap para pelajar atau peserta didik. Hal ini juga untuk mempertegas kecintaan kita terhadap bahasa sendiri agar identitas bangsa kita lebih dihargai dalam skala internasional, sehingga tidak menutup kemungkinan, bahasa Indonesia dapat menjadi bahasa Internasional di masa mendatang.

\section{MASALAH}

Sepanjang kita berada di wilayah negara Indonesia, merupakan suatu keharusan untuk tetap mempergunakan bahasa Indonesia yang baik dan benar sesuai dengan kaidah. Keterbatasan pengetahuan dan pemahaman dalam penggunaan Bahasa Indonesia yang tidak tepat di kalangan masyarakat dan peserta didik, baik lembaga pendidikan formal maupun non formal merupakan persoalan utama yang perlu segera diperhatikan. Berdasarkan permasalahan tersebut, maka lewat kegiatan pengabdian kepada masyarakat dilakukan penyampaian materi, diskusi dan/atau tanya jawab dengan mitra sasaran yang terdiri dari peserta didik, meliputi :

a) Penggunaan bahasa yang baik dan benar

b) Kesalahan dalam berbahasa Indonesia

\section{METODE}

Metode yang digunakan pada kegiatan ini adalah metode pembelajaran yang dikhususkan bagi peserta didik yang berasal dari Sekolah Menengah Pertama (SMP) dan Sekolah Menengah Atas (SMA), yang berada di Panti Asuhan Emiyo Dere Keluruhan Kladufu Distrik Sorong Timur. 


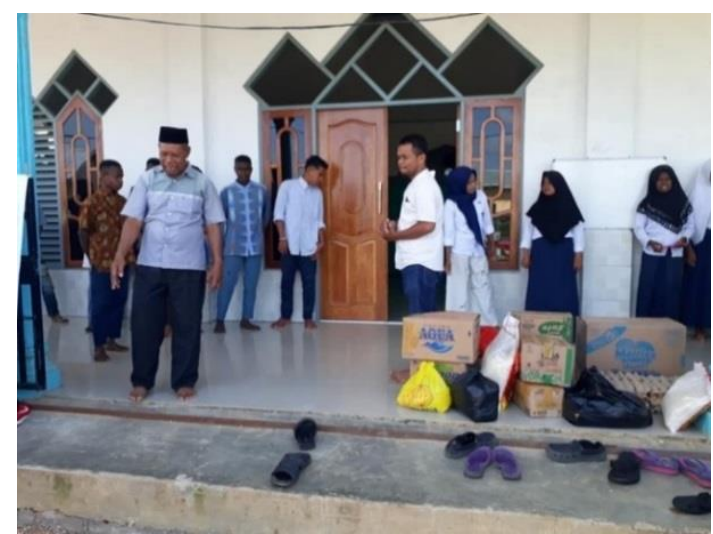

Gambar 1. Penyambutan Tim PkM oleh Pengurus dan anak-anak Panti Asuhan

\section{PEMBAHASAN}

A. Penggunaan bahasa yang baik dan benar

Ada berbagai macam ragam bahasa di Indonesia. Gaya bahasa yang digunakan ketika memberikan laporan kepada atasan, jual beli di pasar, menulis surat kepada kekasih, dan menulis karya ilmiah menunjukkan ragam yang berbeda-beda (Setiawati, 2008). Terdapat 5 ragam dalam laras bahasa yang digunakan, semua ragam dapat digunakan dalam kondisi tertentu :

1) Ragam Resmi (Formal), yaitu bahasa yang dipakai dalam komunikasi resmi seperti rapat resmi, pidato dan jurnal ilmiah. Oleh karena itu, memakai bahasa yang lebih sopan adalah hal yang tepat.

2) Ragam Beku, yaitu bahasa yang digunakan pada acara hikmat dan sedikit memungkinkan keleluasaan seperti upacara pernikahan, keputusan pengadilan dan kegiatan rohani.

3) Ragam Konsultatif, yaitu bahasa yang digunakan dalam pertukaran informasi atau kegiatan transaksi dalam suatu percakapan yang membahas tentang suatu hal yang diketahui oleh masing-masing pembicara seperti percakapan di sekolah atau di pasar.

4) Ragam Akrab, yaitu bahasa yang digunakan diantara orang yang memiliki hubungan sangat akrab atau intim. seperti dalam pembicaraan berumah tangga

5) Ragam Santai (kasual), yaitu bahasa yang digunakan untuk acara yang bersifat tidak resmi dan dapat dipakai untuk orang yang cukup akrab (misalnya teman) atau orang 
yang belum dikenal dengan akrab (baru kenal). seperti pembicaraan dalam perkumpulan dengan teman-teman

Seperti yang sudah dijelaskan sebelumnya bahwa ragam bahasa yang digunakan sebaiknya disesuaikan dengan kondisi atau tempat kita berada. Misalnya dalam situasi santai dan akrab, seperti di warung kopi, pasar, dan lain-lain hendaklah digunakan bahasa Indonesia yang santai dan akrab. Hal ini berbeda ketika kita berada dalam situasi resmi dan formal, seperti kuliah, seminar, dan sebagainya kita harus menggunakan bahasa indonesia yang resmi dan formal yang selalu memperhatikan norma bahasa.
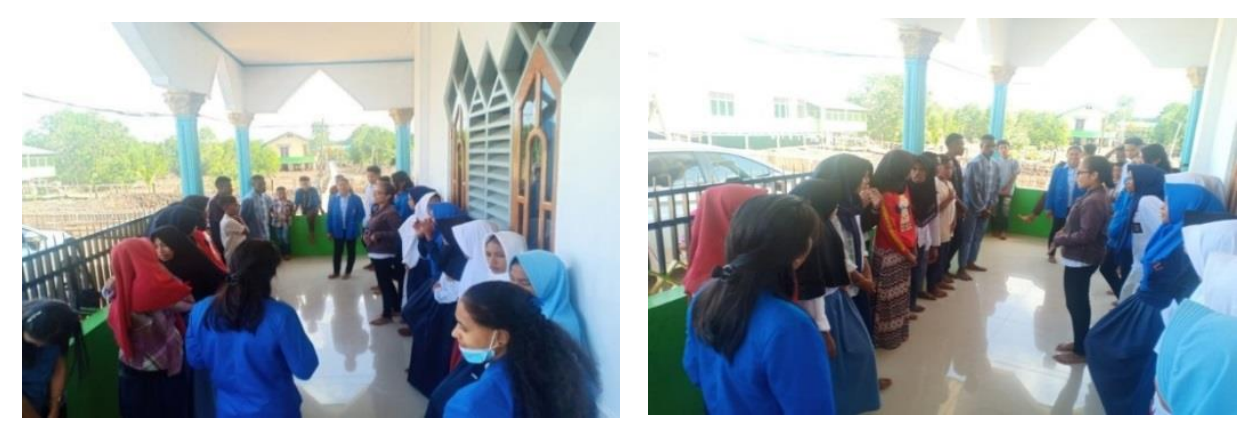

Gambar 2. Permainan antar kelompok berkaitan dengan materi yang diterima

Bahasa Indonesia yang benar adalah bahasa Indonesia yang digunakan sesuai dengan aturan atau kaidah bahasa Indonesia yang berlaku. Kaidah bahasa Indonesia itu meliputi kaidah ejaan, pembentukan kata, kalimat, dan paragraf.

\section{a. Kaidah Ejaan}

Kaidah ejaan sendiri berupa :

1) Pemakaian huruf dan angka (abjad, angka arab, dan angka romawi)

Abjad yang digunakan dalam ejaan bahasa Indonesia terdiri atas 26 huruf berikut ini:

Tabel 1. Abjad dalam Ejaan Bahasa Indonesia

\begin{tabular}{|c|c|c|c|c|c|c|c|c|}
\hline \multicolumn{2}{|c|}{ Huruf } & \multirow{2}{*}{$\frac{\text { Dibaca }}{\mathrm{a}}$} & \multicolumn{2}{|c|}{ Huruf } & \multirow{2}{*}{$\frac{\text { Dibaca }}{\text { je }}$} & \multicolumn{2}{|c|}{ Huruf } & \multirow{2}{*}{$\frac{\text { Dibaca }}{\text { es }}$} \\
\hline $\mathrm{A}$ & $\mathrm{a}$ & & $\mathrm{J}$ & $\bar{j}$ & & $S$ & $\mathrm{~S}$ & \\
\hline B & $b$ & be & K & $\mathrm{k}$ & ka & $\mathrm{T}$ & $\mathrm{t}$ & te \\
\hline $\mathrm{C}$ & $\mathrm{c}$ & ce & $\mathrm{L}$ & 1 & el & $\mathrm{U}$ & $\mathrm{u}$ & $\mathrm{u}$ \\
\hline $\mathrm{D}$ & $\mathrm{d}$ & de & $\mathrm{M}$ & $\mathrm{m}$ & em & $\mathrm{V}$ & e & ve \\
\hline $\mathrm{E}$ & $\mathrm{e}$ & e & $\mathrm{N}$ & $\mathrm{n}$ & en & W & $\mathrm{e}$ & we \\
\hline $\mathrm{F}$ & $\mathrm{f}$ & ef & $\mathrm{O}$ & o & o & $X$ & $\mathrm{X}$ & eks \\
\hline $\mathrm{G}$ & $\mathrm{g}$ & ge & $\mathrm{P}$ & $\mathrm{p}$ & pe & Y & $\mathrm{y}$ & ye \\
\hline $\mathrm{H}$ & $\mathrm{h}$ & ha & Q & $q$ & ki & Z & $\mathrm{Z}$ & zet \\
\hline I & $\mathrm{i}$ & $\mathrm{i}$ & $\mathrm{R}$ & $\mathrm{r}$ & er & & & \\
\hline
\end{tabular}


Angka dipakai untuk menyatakan lambang bilangan atau nomor. Di dalam tulisan, lazim digunakan angka Arab atau angka Romawi, seperti contoh di bawah ini :

Angka Arab : 0, 1, 2, 3, 4, 5, 6, 7, 8, 9, 10, dan seterusnya.

Angka Romawi : I, II, III, IV, V, VI, VII, VIII, IX, X, L (50), dan seterusnya.

2) Penulisan kata (kata dasar dan kata turunan)

a) Kata yang merupakan kata dasar ditulis sebagai satu kesatuan.

Misalnya : Ibu percaya bahwa engkau tahu

Buku itu sangat tebal

b) Kata turunan

Imbuhan (awalan, sisipan, akhiran) ditulis serangkai dengan kata dasarnya. Misalnya: dikelola, bergetar, penetapan, menengok, berlari

Jika bentuk dasar berupa gabungan kata, awalan atau akhiran ditulis serangkai dengan kata yang langsung mengikuti atau mendahuluinya. Misalnya : bertepuk tangan, garis bawahi, sebar luaskan

Jika bentuk dasar yang merupakan gabungan kata mendapat awalan dan akhiran sekaligus, unsur gabungan kata itu ditulis serangkai. Misalnya : pertanggungjawabkan, melipatgandakan, memutarbalikkan, menjualbelikan

Jika imbuhan diberikan pada kata dasar yang berbentuk singkatan atau istilah asing, maka dihubungkan dengan tanda hubung (-). Kata dasar dengan istilah asing dicetak miring. Misalnya : mem-PHK, men-download, di-upload.

3) Penulisan unsur serapan (adopsi atau adaptasi)

Cara adopsi terjadi apabila pemakai bahasa mengambil bentuk dan makna kata asing yang diserap secara keseluruhan, sedangkan cara adaptasi terjadi apabila pemakai bahasa hanya mengambil makna kata asing yang diserap dan ejaan atau cara penulisannya disesuaikan ejaan bahasa Indonesia (Susetyo, 2016).

Contoh adopsi : supermarket (dari kata supermarket), formal (juga dari kata formal), editor (dari kata yang sama yaitu editor).

Contoh adaptasi : maksimal (dari kata maximal), organisasi (dari kata organization), intelektual (dari kata intelectual).

4) Pemakaian tanda baca (Titik (.), koma (,), petik ('.. ') (“ ... “), dan sebagainya) Tanda titik dipakai untuk hal-hal sebagai berikut : 
a) Pada akhir kalimat yang bukan pertanyaan atau seruan.

Misalnya : Ayahku tinggal di Solo.

Biarlah mereka yang duduk di sana.

b) Di belakang angka atau huruf dalam satu bagan, ikhtisar, atau daftar.

Misalnya : III. Departemen Dalam Negeri

A. Direktorat Jenderal Pembangunan

\subsection{Isi karangan}

c) Untuk memisahkan angka jam, menit, dan detik yang menunjukkan jangka waktu.

Misalnya : 1.35 .20 jam (1 jam, 35 menit, 20 detik)

0.20.30 jam (20 menit, 30 detik)

d) Dipakai diantara nama penulis, judul tulisan yang tidak berakhir dengan tanda tanya atau tanda seru, dan tempat terbit dalam daftar pustaka.

Misalnya :

Siregar, Merari. 1920. Azab dan sengsara. Weltervreden : Balai pustaka.

e) Dipakai untuk memisahkan bilangan ribuan atau kelipatannya.

Misalnya : Desa itu berpenduduk 24.200 orang.

Gempa yang terjadi semalam menewaskan 1.231 jiwa

f) Tanda titik tidak dipakai untuk memisahkan bilangan ribuan atau kelipatannya yang tidak menunjukkan jumlah.

Misalnya : Ia lahir pada tahun 1956 di Bandung.

Lihat halaman 2345 dan seterusnya.

g) Tanda titik tidak dipakai pada akhir judul yang merupakan kepala karangan atau kepala ilustrasi, tabel, dan sebagainya.

Misalnya : Acara Kunjungan Adam Malik

Salah Asuhan

Tanda koma dipakai untuk hal-hal sebagai berikut :

a) Dipakai diantara unsur-unsur dalam suatu perincian atau pembilangan.

Misalnya : Saya membeli kertas, pena, dan tinta.

Surat biasa, surat kilat, ataupun surat khusus memerlukan perangko. 
b) Dipakai untuk memisahkan kalimat setara yang satu dari kalimat setara berikutnya yang didahului oleh kata seperti tetapi atau memisahkan.

Misalnya : Saya ingin datang, tetapi hari hujan

Didi bukan anak saya, melainkan anak Pak Kasim.

c) Dipakai untuk memisahkan anak kalimat dari induk kalimat jika anak kalimat itu mendahului induk kalimatnya.

Misalnya : Kalau hari hujan, saya tidak akan datang.

Karena sibuk, ia lupa akan janjinya.

d) Tanda koma tidak dipakai untuk memisahkan anak kalimat dari induk kalimat jika anak kalimat itu mengiringi induk kalimatnya.

Misalnya : Saya tidak akan datang kalau hari hujan.

Dia lupa akan janjinya karena sibuk.

e) Dipakai untuk memisahkan petikan langsung dari bagian lain dalam kalimat.

Misalnya : Kata Ibu, "Saya gembira sekali.”

"Saya gembira sekali," kata Ibu, "kaena kamu lulus."

f) Dipakai diantara nama orang dan gelar akademik yang mengikutinya untuk membedakannya dari singkatan nama diri, keluarga, atau marga.

Misalnya : B. Ratulangi, S.E.

Ny. Khadijah, M.A.

Tanda petik tunggal (') dipakai untuk :

a) Mengapit petikan yang tersusun di dalam petikan lain.

Misalnya : Tanya Basri, "Kau dengar bunyi 'kring-kring' tadi?"

Waktu kubuka pintu depan, kudengar teriak anakku, 'Ibu, Bapak pulang', dan rasa letihku lenyap seketika," ujar Pak Hamdan.

b) Mengapit makna, terjemahan, atau penjelasan kata atau ungkapan asing.

Misalnya : feed-back 'balikan'

Tanda petik (") dipakai untuk :

a) Mengapit petikan langsung yang berasal dari pembicaraan dan naskah atau bahan tertulis lain.

Misalnya : :Saya belum siap,”. Kata Mira, "tunggu sebentar!" 
Pasal 36 UUD 1945, berbunyi, "Bahasa Negara ialah bahasa Indonesia."

b) Mengapit judul syait, karangan, atau bab buku yang dipakai dalam kalimat.

Misalnya : Bacaan "Bola Lampu” dalam buku Dari Suatu Masa, dari Suatu Tempat.

c) Tanda baca penutup kalimat atau bagian kalimat ditempatkan di belakang tanda petik yang mengapit kata atau ungkapan yang dipakai dengan arti khusus pada ujung kalimat atau bagian kalimat.

Misalnya: Karena warna kulitnya, Budi mendapat julukan "Si Hitam”.

Bang Komar sering disebut "pahlawan", ia sendiri tidak tahu sebabnya.

\section{b. Pembentukan Kata}

Pembentukan kata digunakan untuk kata berimbuhan, kata ulang dan kata majemuk.

Berikut adalah contoh penggunaannya :

1) Kata berimbuhan adalah kata yang terdiri dari kata dasar dan imbuhan

Misalnya :

Lari menjadi berlari

Makan menjadi makanan

2) Kata ulang adalah istilah yang berupa ulangan kata dasar seutuhnya atau sebagiannya, dengan atau tanpa pengimbuhan dan perubahan bunyi.

Misalnya :

Rumah menjadi rumah-rumah (pengulangan utuh)

Lari menjadi berlari-lari (pengulangan berimbuhan)

Kuning menjadi kekuning-kuningan (pengulangan berimbuhan)

3) Kata majemuk

Mata dan hari menjadi matahari (senyawa)

Rumah dan sakit menjadi rumah sakit (tidak senyawa)

B. Kesalahan Dalam Berbahasa Indonesia

Menurut Arifin dan Hadi (2015), dalam bahasa terdapat istilah ekonomi bahasa. Artinya, kita harus dapat menggunakan kata-kata dengan sehemat-hematnya. Akan tetapi, penghematan itu jangan sampai merusak kaidah bahasa, apalagi menimbulkan 
salah paham. Kesalahan yang terjadi biasanya dalam pembentukan kata, pemilihan kata, penyusunan kalimat, penerapan ejaan, dan surat menyurat.

1) Kesalahan Pembentukan Kata

Kesalahan umum :

a) Presiden lantik lima orang duta besar.

b) Amerika Serikat luncurkan pesawat ke Columbia.

c) Ketika saya datang, mereka sudah kumpul di rumah.

d) Kita harus dapat merubah kebiasaan yang kurang terpuji, menjadi kebiasaan yang baik.

e) Kita semua harus ikut serta mensukseskan kegiatan itu.

Yang dianjurkan :

a) Presiden melantik lima orang duta besar.

b) Amerika Serikat meluncurkan pesawat ke Columbia.

c) Ketika saya datang, mereka sudah berkumpul di rumah.

d) Kita harus dapat mengubah kebiasaan yang kurang terpuji, menjadi kebiasaan yang baik.

e) Kita semua harus ikut serta menyukseskan kegiatan itu.

2) Kesalahan Pemilihan Kata

Pemilihan kata yang kurang tepat akan membentuk kalimat yang samar-samar. Ada juga pemilihan kata yang tidak tepat yang masih dapat dipahami orang lain, tetapi dari segi kaidah bahasa, kata yang dipilihnya tidak termasuk kata yang baku. Kesalahan umum :

a) Kita harus dapat memelihara dan mengamankan daripada hasil pembangunan

b) Itulah rumah di mana terjadinya pembunuhan yang kejam itu.

c) Saya pernah bilang hal itu kepadamu.

d) Banyak jalan yang rusak karena tidak sesuai konstruksi yang digariskan semula.

e) Para peserta pertemuan itu terdiri beberapa pakar dari berbagai disiplin ilmu.

Yang dianjurkan :

a) Kita harus dapat memelihara dan mengamankan hasil pembangunan

b) Itulah rumah tempat terjadinya pembunuhan yang kejam itu. 
c) Saya pernah mengatakan hal itu kepadamu.

d) Banyak jalan yang rusak karena tidak sesuai dengan konstruksi yang digariskan semula.

e) Para peserta pertemuan itu terdiri atas beberapa pakar dari berbagai disiplin ilmu.

3) Kesalahan Penyusunan Kalimat

Sebuah kalimat hendaklah berisikan suatu gagasan atau ide. Agar gagasan atau ide kalimat mudah dipahami pembaca, fungsi bagian kalimat yang meliputi subjek, predikat, objek, dan keterangan harus tampak dengan jelas (eksplisit).

Kesalahan umum :

a) Di Jakarta akan mengadakan pameran pembangunan selama bulan Agustus tahun ini.

b) Melalui penelitian ini akan memberikan manfaat yang besar bagi pengembangan pariwisata di tanah air.

Kedua kalimat diatas (a dan b) tergolong dalam kalimat yang tidak baku karena tidak memiliki subjek.

c) Kandungan zat kimia tertentu dalam limbah industri yang mencemari perairan dalam jumlah tertentu yang dapat membahayakan kehidupan sumber hayati perikanan penghuni perairan tersebut.

d) Beberapa kasus pencemaran perairan yang disebabkan oleh kegiatan industri di tanah air dewasa ini memperlihatkan kepada kita bahwa hal tersebut yang diakibatkan oleh pembuangan limbah tidak terkendali, baik yang disengaja maupun yang tidak.

Kedua kalimat diatas (c dan d) tergolong dalam kalimat yang belum berpredikat karena adanya keterangan subjek yang beruntun. Misalnya sebelum predikat dicantumkan kata yang atau dan sehingga predikat kalimat menjadi hilang.

e) Tujuan memarut adalah untuk melepaskan daging kelapa menjadi butiran-butiran halus. Sehingga pada tahap pemerasan, butiran-butiran halus dapat dengan mudah diperas untuk mendapatkan santan atau minyak.

f) Menurunnya produksi padi sekarang disebabkan oleh berbagai faktor. Seperti musim kering yang panjang dan hama wereng yang merajalela.

Kalimat e) dan f) disebut kalimat terpenggal atau kalimat bunting karena sebenarnya masih mempunyai hubungan gantung dengan kalimat lainnya. Kalimat yang 
mempunyai hubungan gantung itu disebut anak kalimat, sedangkan kalimat yang digantunginya disebut induk kalimat.

g) Semua pelajar harus belajar sungguh-sungguh demi untuk kejayaan bangsa dan masa depan.

h) Berbuat baik kepada ibu dan bapak guru adalah merupakan kewajiban kita semua. Kalimat g) dan h) merupakan kalimat yang tidak tepat karena didalamnya terdapat pemakaian dua kata yang mengandung makna yang sama.

Yang dianjurkan :

a) Di Jakarta akan diadakan pameran pembangunan Jakarta akan mengadakan pameran pembangunan

b) Penelitian ini akan memberikan manfaat yang besar bagi pengembangan pariwisata di tanah air.

c) Kandungan zat kimia tertentu dalam limbah industri yang mencemari perairan dalam jumlah tertentu dapat membahayakan kehidupan sumber hayati perikanan yang menghuni perairan tersebut.

d) Beberapa kasus pencemaran perairan yang disebabkan oleh kegiatan industri di tanah air dewasa ini memperlihatkan kepada kita bahwa hal tersebut diakibatkan oleh pembuangan limbah yang tidak terkendali, baik yang disengaja maupun tidak.

e) Tujuan memarut adalah untuk melepaskan daging kelapa menjadi butiran-butiran halus sehingga pada tahap pemerasan, butiran-butiran halus dapat dengan mudah diperas untuk mendapatkan santan atau minyak.

f) Menurunnya produksi padi sekarang disebabkan oleh berbagai faktor, seperti musim kering yang panjang dan hama wereng yang merajalela.

g) Semua pelajar harus belajar sungguh-sungguh untuk kejayaan bangsa dan masa depan.

Semua pelajar harus belajar sungguh-sungguh demi kejayaan bangsa dan masa depan.

h) Berbuat baik kepada ibu dan bapak guru adalah kewajiban kita semua.

Berbuat baik kepada ibu dan bapak guru merupakan kewajiban kita semua. 
C. Penyerahan bantuan

Selain penyampaian materi kepada para peserta, kegiatan pengabdian kepada masyarakat ini juga disertai dengan penyerahan bantuan kepada anak-anak Panti berupa bahan makanan dan pakaian layak pakai.

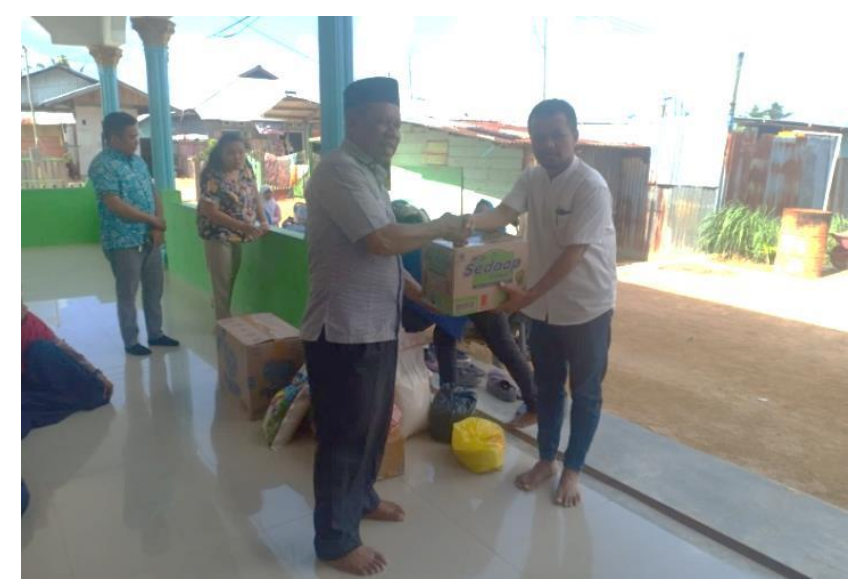

Gambar 3. Penyerahan bantuan kepada anak-anak Panti Asuhan Emiyo Dere

Bantuan diserahkan langsung kepada pengurus Panti Asuhan Emiyo Dere Keluruhan Kladufu Distrik Sorong Timur dan nantinya akan diteruskan kepada anak-anak panti.

\section{KESIMPULAN}

Keterbatasan pengetahuan dan pemahaman dalam penggunaan Bahasa Indonesia yang tidak tepat di kalangan masyarakat dan peserta didik, baik lembaga pendidikan formal maupun non formal merupakan persoalan utama yang perlu segera diperhatikan. Dengan demikian, peningkatan mutu penggunaan bahasa Indonesia perlu dilakukan secara berkesinambungan karena perubahan-perubahan yang terjadi oleh adanya kemajuan teknologi akan mempengaruhi perilaku masyarakat dalam berbahasa. Pelaksanaan pengabdian kepada masyarakat yang dilaksanakan di Panti Asuhan Emiyo Dere Keluruhan Kladufu Distrik Sorong Timur diharapkan dapat menumbuhkan kesadaran dari peserta didik yang ada, bukan hanya terhadap penggunaan bahasa Indonesia yang baik dan benar sesuai dengan kaidah yang berlaku (meliputi kaidah ejaan, pembentukan kata, kalimat, dan paragraf) tetapi juga terhadap kesalahan yang terjadi biasanya dalam pembentukan kata, pemilihan kata, dan penyusunan kalimat. Pemberian materi tentang penggunaan Bahasa Indonesia ini harus terus diperdalam di setiap lembaga pendidikan, baik pada tingkat Sekolah Menengah Pertama (SMP) maupun Sekolah Menengah Atas (SMA) melalui kurikulum yang telah ada. 


\section{DAFTAR PUSTAKA}

Alwi H., Dardjowidjojo Soenjono, Lapoliwa H., Moeliono Anton. 2010. Tata Bahasa Baku Bahasa Indonesia. Pusat Bahasa dan Balai Pustaka. Jakarta

Arifin Zaenal dan Hadi Farid. 2015. Seribu Satu Kesalahan Berbahasa. Akademika Pressindo. Jakarta

Kementerian Hukum dan Hak Asasi Manusia Republik Indonesia. 2019. Peraturan Presiden Republik Indonesia Nomor 63 Tahun 2019 Tentang Penggunaan Bahasa Indonesia. Jakarta. Ditetapkan dan diundangkan pada tanggal 30 September 2019

Majelis Permusyawaratan Rakyat Republik Indonesia. Undang-Undang Dasar Negara Republik Indonesia Tahun 1945 Dalam Satu Naskah

Redaksi Lima Adi Sekawan. 2007. EYD Plus. Limas. Jakarta

Setiawati Eti. 2008. Bahasa Indonesia Keilmuan Dalam Karya Tulis Ilmiah. Surya Pena Gemilang. Malang

Susetyo Agus Milu. 2016. Penggunaan Kata dan Istilah Bahasa Inggris Pada Rubrik Opini Surat Kabar Kompas. Jurnal Ilmiah Program Studi Bahasa dan Sastra Indonesia. Belajar Bahasa Volume 1 Nomor 1 Februari 2016. ISSN 2502-5864, E-ISSN 2503-0329. 